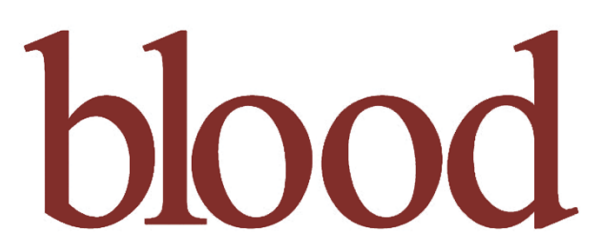

2006 107: 2976-2983

Prepublished online Nov 29, 2005;

doi:10.1182/blood-2005-06-2562

\title{
A novel murine model of fetal and neonatal alloimmune thrombocytopenia: response to intravenous IgG therapy
}

Heyu Ni, Pingguo Chen, Christopher M. Spring, Ebrahim Sayeh, John W. Semple, Alan H. Lazarus, Richard O. Hynes and John Freedman

Updated information and services can be found at:

http://bloodjournal.hematologylibrary.org/cgi/content/full/107/7/2976

Articles on similar topics may be found in the following Blood collections:

Hemostasis, Thrombosis, and Vascular Biology (2496 articles)

Transfusion Medicine (177 articles)

Information about reproducing this article in parts or in its entirety may be found online at:

http://bloodjournal.hematologylibrary.org/misc/rights.dtl\#repub_requests

Information about ordering reprints may be found online at:

http://bloodjournal.hematologylibrary.org/misc/rights.dtl\#reprints

Information about subscriptions and ASH membership may be found online at:

http://bloodjournal.hematologylibrary.org/subscriptions/index.dtl

Blood (print ISSN 0006-4971, online ISSN 1528-0020), is published semimonthly by the American Society of Hematology, $1900 \mathrm{M} \mathrm{St}$, NW, Suite 200, Washington DC 20036.

Copyright 2007 by The American Society of Hematology; all rights reserved.

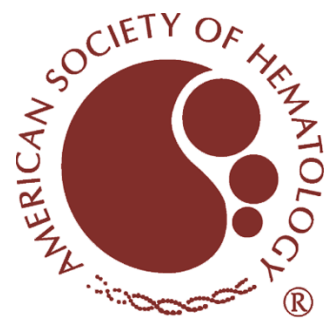




\title{
A novel murine model of fetal and neonatal alloimmune thrombocytopenia: response to intravenous IgG therapy
}

\author{
Heyu Ni, Pingguo Chen, Christopher M. Spring, Ebrahim Sayeh, John W. Semple, Alan H. Lazarus, Richard O. Hynes, and John Freedman
}

Fetal and neonatal alloimmune thrombocytopenia (FNAITP) is a life-threatening bleeding disorder caused by maternal antibodies directed against fetal platelet antigens. The immunoreactive epitopes in FNAITP are primarily located in the extracellular regions of the platelet glycoprotein Illa ( $\beta_{3}$ integrin). Here we have established a novel animal model of FNAITP using $\beta_{3}$ integrin-deficient $\left(\beta_{3}{ }^{-l-}\right)$ mice. We demonstrated first that these mice are immunoresponsive to $\beta_{3}$ integrin; $\beta_{3}{ }^{-l-}$ mice transfused with wild-type platelets generated specific anti- $\boldsymbol{\beta}_{3}$ antibodies which were able to induce thrombocytopenia in wild-type mice. Subsequently, $\boldsymbol{\beta}_{3}{ }^{-l-}$ female mice (both naive and immunized) were bred with wild-type male mice to recapitulate the features of FNAITP. The titer of generated maternal antibodies correlated with the severity of FNAITP. High titer maternal anti- $\boldsymbol{\beta}_{3}$ anti- bodies caused severe fetal thrombocytopenia, intracranial hemorrhage, and even miscarriage. Furthermore, maternal administration of intravenous immunoglobulin G (IgG) ameliorated FNAITP and downregulated pathogenic antibodies in both the maternal and fetal circulations. (Blood. 2006;107:2976-2983)

(ㄱ) 2006 by The American Society of Hematology

\section{Introduction}

Fetal and neonatal alloimmune thrombocytopenia (FNAITP) is an alloimmune disorder which results from maternal antibodies that cross the placenta, bind to fetal platelets, and mediate fetal platelet destruction. The frequency of FNAITP is estimated at 0.5 to 1.5 per 1000 liveborn neonates. ${ }^{1,2}$ The major risk of FNAITP is intracranial hemorrhage (ICH) with neurologic impairment or death. After birth, ICH occurs in $10 \%$ to $20 \%$ of neonates with FNAITP, and may be fatal in up to $5 \%$ of cases. ${ }^{3}$

There are at least 16 recognized human platelet antigens (HPAs), and immunoreactivity to the different HPAs can cause FNAITP. ${ }^{4}$ These antigens result from polymorphisms in the glycoproteins (GPs) on the platelet surface such as GPIaIIa $\left(\alpha_{2} \beta_{1}\right.$ integrin), GPIb $\alpha$, and GPIIbIIIa ( $\alpha_{\mathrm{IIb}} \beta_{3}$ integrin). Amino acid sequences inherited from the father that differ from those of the mother may be targeted by the maternal immune system. Most cases of FNAITP are due to incompatibility in the amino acid sequence of the $\beta_{3}$ integrin subunit. HPA-1a (polymorphism of residue 33 in the $\beta_{3}$ subunit) is the most common antigen causing FNAITP in white newborns, accounting for $75 \%$ to $95 \%$ of clinical FNAITP cases. ${ }^{5}$ HPA-4a (polymorphism in residue 143 of the $\beta_{3}$ subunit) is the most common antigen causing FNAITP in Asian newborns. ${ }^{6}$ In addition, incompatibility in residues 62, 140, 407,
$489,611,633$, and 636 of the $\beta_{3}$ subunit has also been reported. ${ }^{4}$ Thus, a variety of alloantigens are located throughout the extracellular $\beta_{3}$ integrin subunit and study of the immune response to the entire $\beta_{3}$ integrin subunit is of importance to the understanding of FNAITP.

The process of the maternal immune response to fetal platelet antigens is largely unknown. The mechanism by which alloantibodies cross the placenta is also not fully understood, although the neonatal $\mathrm{Fc}$ receptor $(\mathrm{FcRn})$ has been implicated as a receptor that mediates placental immunoglobulin $\mathrm{G}$ (IgG) transport and controls homeostasis of IgG levels in the circulation. ${ }^{7,8}$ Furthermore, although it has been hypothesized that the mechanism of platelet destruction may be similar to that of idiopathic thrombocytopenic purpura (ITP), ${ }^{9}$ the pathogenesis of thrombocytopenia in FNAITP has not yet been clearly established.

Effective therapy for FNAITP is currently limited. Compatible (antigen-negative) platelets for transfusion are often difficult to obtain on short notice. In contrast, intravenous IgG (IVIG) can be readily and quickly made available. IVIG is thus an attractive candidate for the treatment of FNAITP. While IVIG has been reported to alleviate FNAITP, the results from different investigators are conflicting and no randomized trials have been reported. ${ }^{1,10}$
From the Departments of Laboratory Medicine and Pathobiology, Medicine, and Pharmacology, University of Toronto, ON, Canada; The Canadian Blood Services, Ottawa, ON, Canada; The Toronto Platelet Immunobiology Group, St Michael's Hospital, Toronto, ON, Canada; and the Department of Biology, Howard Hughes Medical Institute and Center for Cancer Research, Massachusetts Institute of Technology, Cambridge, MA.

Submitted June 29, 2005; accepted November 16, 2005. Prepublished online as Blood First Edition Paper, November 29, 2005; DOI 10.1182/blood-2005-062562.

Supported in part by the start-up funds from Canadian Blood Services and St Michael's Hospital (H.N.); Dean's Fund of University of Toronto (H.N.); Bayer/ Canadian Blood Services/Hema-Quebec/Canadian Institutes of Health Research Partnership Fund (H.N., principal investigator [PI]; and J.F., co-PI); and Canadian Institutes of Health Research grant no. 129403 (H.N., PI; and J.F., co-PI); National Institutes of Health grant PO1-HL66105 (R.O.H.). E.S. is a fellow of the Keenan Foundation at St Michael's Hospital.
H.N. designed the experiments, analyzed data, and wrote the manuscript; P.C. performed the research, analyzed data, and wrote the manuscript; C.M.S. performed the research, and edited the manuscript; E.S. performed the research, and analyzed data; J.W.S. analyzed data, and edited the manuscript; A.H.L. analyzed data, and edited the manuscript; R.O.H. provided vital reagents $\left(\beta 3^{--}\right.$mice) and edited the manuscript; and J.F. provided analytic tools (flow cytometer), analyzed data, and edited the manuscript.

Reprints: Heyu Ni, Canadian Blood Services and Dept of Laboratory Medicine and Pathobiology, St Michael's Hospital, University of Toronto, 30 Bond St Rm 2-006, Bond Wing, Toronto, ON, Canada M5B 1W8; e-mail: nih@smh. toronto.on.ca.

The publication costs of this article were defrayed in part by page charge payment. Therefore, and solely to indicate this fact, this article is hereby marked "advertisement" in accordance with 18 U.S.C. section 1734.

@ 2006 by The American Society of Hematology 
The mechanism of action of IVIG in the treatment of FNAITP and ITP is under intensive study, but remains incompletely understood. ${ }^{11-13}$ Given the ethical difficulties in performing basic research on human fetuses and neonates with this life-threatening disorder, an animal model of FNAITP would be very useful to investigate the pathogenesis of the disorder and evaluate the efficacy and mechanism of action of IVIG in FNAITP.

In this study, we established a novel murine model of FNAITP that recapitulates features of the human pathologic condition, and demonstrated that maternal IVIG administration has a systemic effect on the amelioration of this disease.

\section{Materials and methods}

\section{Mice}

$\beta_{3}{ }^{-1-}$ mice were previously described ${ }^{14}$ and have been backcrossed onto a $\mathrm{BALB} / \mathrm{c}$ background; control wild-type (WT) BALB/c mice (6 to 8 weeks of age) were purchased from Charles River Laboratories (Montreal, QC, Canada). All mice were housed in the St Michael's Hospital Research Vivarium and the experimental procedures were approved by the Animal Care Committee.

\section{Reagents}

IVIG and human albumin were obtained from Bayer Inc/Canadian Blood Services (Elkhart, IN). Alkaline phosphatase-conjugated anti-goat and anti-human IgG as well as anti-mouse polyvalent immunoglobulin and FITC-conjugated anti-mouse IgG, were purchased from Sigma (St Louis, $\mathrm{MO})$. FITC-conjugated anti-mouse $\mathrm{IgG}_{1}$ and $\mathrm{IgG}_{2 \mathrm{a}}$ as well as anti-human IgG were purchased from BD Biosciences (Mississauga, ON, Canada). Goat anti-human $\beta_{3}$ integrin polyclonal antibody (sc-6627) and donkey anti-goat IgG alkaline phosphatase were purchased from Santa Cruz Biotechnology (Santa Cruz, CA). Rat anti-mouse $\alpha_{\text {IIb }} \beta_{3}$ integrin (JON2) and GPIb $\alpha$ (p0p3) monoclonal antibodies were kindly provided by $\mathrm{Dr}$ Nieswandt (Wurzburg, Germany). Bovine serum albumin (BSA), Tween20, and 5-bromo-4-chloro-3-indolyl phosphate (BCIP)/nitroblue tetrazolium (NBT) were purchased from Sigma.

\section{Induction and treatment of neonatal alloimmune thrombocytopenia}

$\beta_{3}{ }^{-l-}$ female mice were immunized with WT mouse platelets in either 2 or 4 weekly transfusions $\left(10^{8}\right.$ platelets/transfusion). After immunization, mice were bled via the saphenous vein and sera were collected to test anti-mouse $\beta_{3}$ integrin IgG. The immunized female $\beta_{3}{ }^{-1-}$ mice were then bred with a WT male mouse. After delivery, platelet counts and bleeding disorders in pups, as well as IgG anti-mouse $\beta_{3}$ integrin in both the mother and pups were analyzed to determine whether the pups exhibited FNAITP. We also set up breeding cages of WT $\times \mathrm{WT}, \beta^{-{ }^{--}} \times \beta_{3}{ }^{-I-}$ and naive $\beta_{3}{ }^{-l-} \times \mathrm{WT}$ mice as controls. For IVIG treatment, female $\beta_{3}{ }^{-1-}$ mice which demonstrated FNAITP in their first deliveries were injected intravenously with $300 \mu \mathrm{L}$ of $10 \%$ IVIG $(1 \mathrm{~g} / \mathrm{kg})$ each week after being bred with WT male mice. Human albumin $(1 \mathrm{~g} / \mathrm{kg})$ was used as a control. To confirm the effect of IVIG, immunized $\beta_{3}{ }^{-1-}$ female mice were also treated with IVIG and albumin after breeding with WT male mice during their first pregnancies.

\section{Detection of anti-mouse $\beta_{3}$ integrin antibodies in immunized mice by flow cytometry}

Blood samples were collected from saphenous veins of $\beta_{3}{ }^{-1-}$ mice which were immunized with WT platelets. Sera were prepared by centrifuging clotted whole blood at $13400 \mathrm{~g}$ for 5 minutes. $\mathrm{IgG}, \mathrm{IgG}_{1}$, and $\mathrm{IgG}_{2 \mathrm{a}}$ antibodies were detected using a 1:100 dilution of sera which was allowed to bind WT platelets at room temperature for 1 hour, centrifuged at $600 \mathrm{~g}$ for 15 minutes, and washed with phosphate-buffered saline (PBS). The bound antibodies were detected with FITC-conjugated goat anti-mouse IgG, rat anti-mouse $\operatorname{IgG}_{1}$, and $\operatorname{IgG}_{2 \mathrm{a}}$, respectively, and analyzed on a FACScan flow cytometer (Becton Dickinson, San Jose, CA). The value for anti-platelet $\mathrm{IgG}$ level was calculated as a fold increase ratio. Fold $=$ mean fluorescent intensity (MFI) of test serum/MFI of preimmune serum.

\section{Immunoprecipitation}

Designated primary antibody ( $4 \mu \mathrm{g}$ of either a well-characterized monoclonal antibody to murine $\beta_{3}$ integrin [JON2], or GPIb $\alpha$ [p0p3], or antisera from the immunized $\beta_{3}{ }^{-1-}$ mice) and $20 \mu \mathrm{L}$ of Protein G Sepharose beads (Amersham Pharmacia Biotech, Baie d'Urfe, QC, Canada) were added to lysates from $10^{8}$ platelets and mixed end-over-end at $4{ }^{\circ} \mathrm{C}$ for 1 hour. Beads were pelleted at $2300 \mathrm{~g}$ and washed 4 times with $800 \mu \mathrm{L}$ of lysis buffer (0.5\% NP-40, $50 \mathrm{mM}$ Tris, $150 \mathrm{mM} \mathrm{NaCl}, 1 \mathrm{mM}$ PMSF, $5 \mu \mathrm{g} / \mathrm{mL}$ leupeptin, and 1mM EDTA). Beads were then incubated in $60 \mu \mathrm{L}$ of $2 \times$ protein sample buffer $(0.004 \%$ bromophenol blue, $50 \mathrm{mM}$ Tris [pH 6.8], $1 \%$ SDS, and 5\% sucrose) and boiled for 10 minutes. Beads were pelleted at $18300 \mathrm{~g}$ for 30 seconds, and the supernatant was loaded on a 7\% denaturing SDS-polyacrylamide gel electrophoresis (PAGE). Subsequently, the proteins were transferred and Western blotted in the same manner as described in "Detection of anti-mouse $\beta_{3}$ integrin antibodies by Western blotting."

\section{Detection of anti-mouse $\beta_{3}$ integrin antibodies by Western blotting}

Mouse platelets $\left(2 \times 10^{6}\right)$ were lysed, and the lysates from either WT or $\beta_{3}{ }^{-1-}$ mice were separated on a $10 \%$ SDS-PAGE gel under nonreducing conditions. After transfer to PVDF membrane (Hybond-P; Amersham Pharmacia Biotech), membrane was immunoblotted with either antisera from the immunized $\beta_{3}^{-1-}$ female mice or sc-6627 goat anti-human $\beta_{3}$ integrin antibody, which cross-reacts with murine $\beta_{3}$ integrin, at room temperature overnight, and incubated with alkaline phosphatase-conjugated anti-mouse polyvalent immunoglobulin or anti-goat IgG. Immunoreactive bands were developed by reaction with substrate (BCIP/NBT).

\section{Induction of thrombocytopenia with antisera from immunized $\beta_{3}{ }^{-l-}$ mice}

WT BALB/c mice were bled via the saphenous vein and the initial platelet count was determined for each mouse and $100 \mu \mathrm{L}$ antisera or their dilutions from immunized $\beta_{3}{ }^{-l-}$ mice (2- and 4-platelet transfusions) was injected via the tail vein on day 1 . Platelet counts for individual mice were enumerated daily up to day 4 .

\section{Platelet enumeration}

As previously described, ${ }^{11}$ whole blood $(10 \mu \mathrm{L})$ was isolated from either adult mice (saphenous bleeding) or pups (carotid bleeding) and diluted into $990 \mu \mathrm{L}$ of $1 \%$ EDTA in PBS. The blood was then further diluted in PBS to a final dilution of 1:12 000. A total of 20 to $30 \mu \mathrm{L}$ of whole blood from the pups was collected after carotid bleeding for platelet counts and antibody detection. The samples were analyzed for 2 minutes on a flow ratecalibrated FACScan flow cytometer, using forward scatter (FSC) versus side scatter (SSC) to gate platelets. Reference samples were incubated with FITC-conjugated anti-mouse CD61 antibody to identify the platelet population.

\section{Detection of free-circulating IgG against platelets and platelet-associated IgG in heterozygous pups}

To detect platelet-associated $\operatorname{IgG}$ (PAIgG), platelets were prepared from $5 \mu \mathrm{L}$ whole blood from heterozygous pups and stained directly with FITC-conjugated anti-mouse IgG for 30 minutes and analyzed with a FACScan flow cytometer. For the determination of free-circulating antiplatelet IgG, sera from heterozygous pups were incubated with $10^{6}$ WT platelets at a 1:10 dilution for 1 hour, centrifuged at $600 \mathrm{~g}$ for 15 minutes, and washed with PBS. Binding of IgG anti-mouse platelet $\beta 3$ integrin was assessed as described in "Detection of anti-mouse $\beta_{3}$ antibodies in immunized mice by flow cytometry." 


\section{Detection of IVIG in maternal and neonatal circulations by ELISA}

Sera from heterozygous pups or female $\beta_{3}{ }^{-1-}$ mice were serially diluted in PBS and coated $(100 \mu \mathrm{L} /$ well $)$ on 96 -well plates at $4{ }^{\circ} \mathrm{C}$ overnight. Plates were then washed 3 times with $0.5 \%$ Tween-20 in PBS and blocked with $2 \%$ BSA in PBS for 3 hours. Plates were then washed with $0.5 \%$ Tween-20/PBS and incubated with 1:1000 alkaline phosphatase-conjugated goat anti-human $\operatorname{IgG}(\gamma$-chain specific) for 30 minutes. The color was developed with p-nitrophenyl phosphate as substrate and the optical density at $405 \mathrm{~nm}\left(\mathrm{OD}_{405}\right)$ values were recorded on a multiwell plate reader.

\section{Anti-idiotype activity of IVIG to the anti-mouse $\beta_{3}$ integrin antibody}

IVIG $(10 \mu \mathrm{g} / \mathrm{mL})$ was preincubated with antisera from the immunized $\beta_{3}{ }^{-I-}$ mice in test tubes at a ratio of $1: 1$ and incubated at $4^{\circ} \mathrm{C}$ overnight. Samples were diluted to a final dilution of 1:100 and then added to WT mouse platelets $\left(10^{6}\right)$ for 1 hour at room temperature. Antisera and IVIG alone were used as positive and negative controls, respectively. The samples were centrifuged at $600 \mathrm{~g}$ for 15 minutes, washed with PBS, incubated with FITC-conjugated goat anti-mouse IgG or FITCconjugated monoclonal mouse anti-human IgG, and then assayed by a FACScan flow cytometer.

\section{Statistical analysis}

Data are presented as means \pm SEM. Differences between 2 groups were assessed by Student unpaired $t$ test or $\chi^{2}$ test as indicated.

\section{Results}

\section{$\beta_{3}{ }^{-1-}$ mice are immunoresponsive to platelet $\beta_{3}$ integrin}

Immune responsiveness of $\beta_{3}^{-1-}$ mice to platelet $\beta_{3}$ integrin antigen is a prerequisite to establish a mouse model of FNAITP. To test this immune responsiveness, we first immunized $\beta_{3}{ }^{-/-}$mice by weekly transfusions of $10^{8} \mathrm{WT}$ platelets. The mice were highly responsive to platelet $\beta_{3}$ integrin antigen and antiplatelet antibody was detected after 2 weekly transfusions of WT platelets. Both $\mathrm{IgG}_{1}$ and $\mathrm{IgG}_{2 \mathrm{a}}$ antibodies were detected (ie, both T-helper 1 [Th1] and Th2-like immune responses existed in ${\beta_{3}}^{-1-}$ mice; Figure 1A). The antibodies were specific to $\beta_{3}$ integrin since they did not recognize either platelets from $\beta_{3}{ }^{-l-}$ mice or WT red blood cells (Figure 1A). An increased titer of anti- $\beta_{3}$ integrin $\mathrm{IgG}$ was found after 4 weekly transfusions of WT platelets (Figure 1B), and these antibodies were also detected by Western blot (Figure 1C). Immunoprecipitating platelet lysates with either these antibodies, the well-characterized rat monoclonal antibody JON2 (anti-mouse $\beta_{3}$ integrin), or p0p3 (anti-mouse GPIb $\alpha$ control), and subsequent immunoblotting further confirmed the specificity of these antibodies (Figure 1D). Notably, the antibodies from the immunized mice induced thrombocytopenia when injected into WT BALB/c mice and a similar extent of thrombocytopenia was observed when high-titer antisera from 4-times-transfused mice was diluted to a titer comparable with that of the twice-transfused mice (Figure 1E).

\section{Maternal anti- $\boldsymbol{\beta}_{3}$ integrin antibodies caused fetal and neonatal bleeding disorders and promoted fetal miscarriage}

To establish a murine model of FNAITP, and to determine if a clinically relevant bleeding disorder could be observed during pregnancy and following delivery, naive female $\beta_{3}{ }^{-1-}$ mice (preimmunization) were bred with WT male mice. However, anti- $\beta_{3}$ integrin IgG was not detectable in these $\beta_{3}{ }^{-1-}$ mice after the first and the second deliveries. Anti- $\beta_{3}$ antibodies were detected in the mothers at low levels by a flow cytometric assay and Western blot in the third and subsequent deliveries (Figure 2A-B). Correspondingly, platelet counts in pups from the first 2 deliveries were not significantly decreased (Figure 3A), and bleeding disorders were not observed (Figure $3 \mathrm{Bi}$ ). Since the female mice were
A

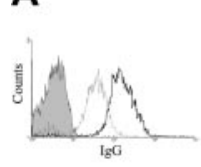

WT RBC
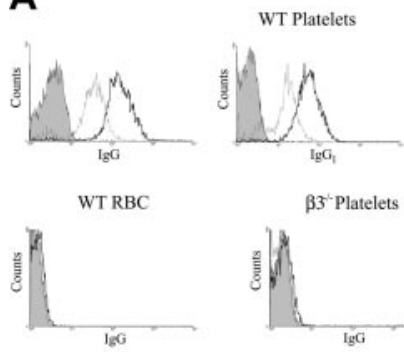

$\beta 3$ Platelets

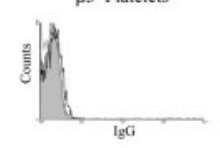

D

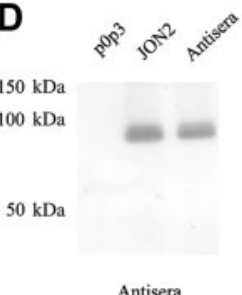

Antisera
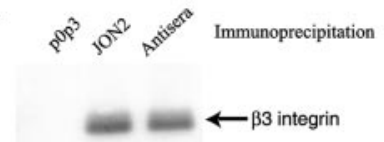

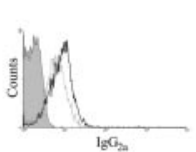

B
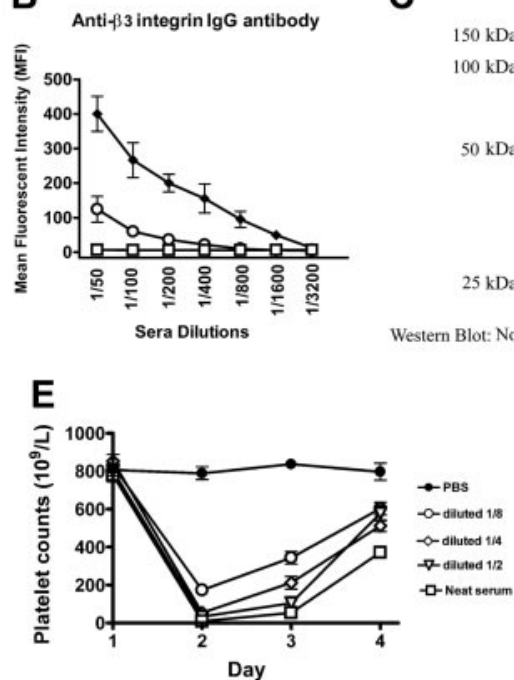
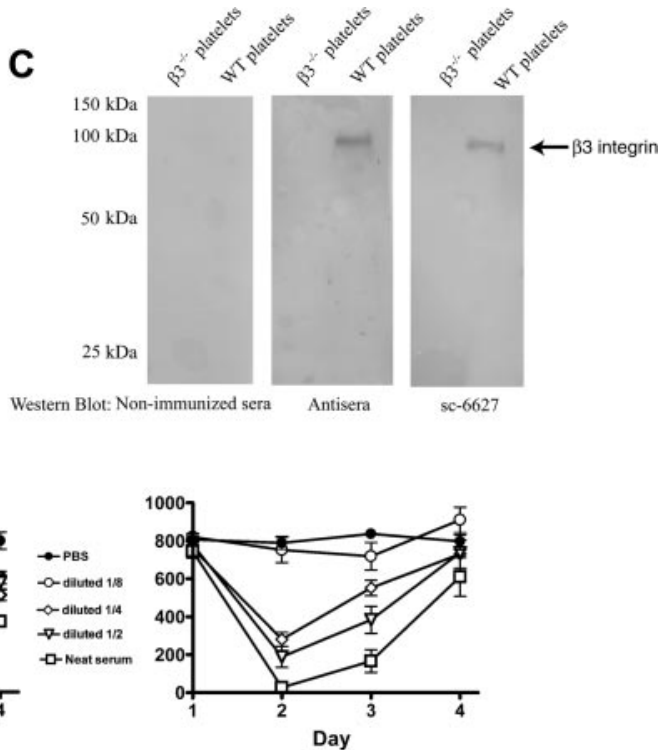

Figure 1. Murine anti- $\boldsymbol{\beta} 3$ integrin antibodies were generated after immunizing $\boldsymbol{\beta}_{3}{ }^{-1-}$ female mice with wild-type mouse platelets. (A) WT mouse platelets were incubated with a 1:100 dilution of sera from $\beta_{3}{ }^{-1-}$ mice immunized either 2 or 4 times weekly (dotted line indicates 2 times; bold line, 4 times) or preimmune sera (filled area) and stained with FITC-conjugated goat anti-mouse IgG or rat anti-mouse $\lg \mathrm{G}_{1}$ or $\lg \mathrm{G}_{2 \mathrm{a}} \beta_{3^{-1-}}$ platelets or WT red blood cells (RBCs) were used as negative controls. (B) Titration of $\lg G$ antibody in preimmune sera of $\beta_{3}{ }^{-1-}$ mice $(\square)$, and sera of mice after $2(\bigcirc)$ or 4 ( $\downarrow$ ) WT platelet transfusions. (C) Western blot of platelet lysates with both control anti- $\beta_{3}$ integrin antibody sc-6627 and antisera of mice after 4 WT platelet transfusions. No $\beta_{3}$ integrin band was recognized by sera from nonimmunized $\beta_{3}{ }^{-1-}$ mice in the negative control. (D) $\beta_{3}$ integrin was immunoprecipitated from platelet lysates using either antisera from this study or the monoclonal antibody JON2 (anti-mouse $\beta_{3}$ integrin) or p0p3 (anti-mouse GPIb $\alpha$, negative control). The $\beta_{3}$ integrin immunoreactive band was detected by both the antisera (left panel) and the positive control antibody sc-6627 (right panel) in immunoblot analysis. (E) Thrombocytopenia was induced in WT BALB/c mice by $100 \mu \mathrm{L}$ antisera and their dilutions from the $\beta_{3}{ }^{-1-}$ mice transfused 2 times (right panel) or 4 times (left panel) with WT platelets. PBS was used as a control. $n=3$ in each group. Data are represented as means \pm SEM. 


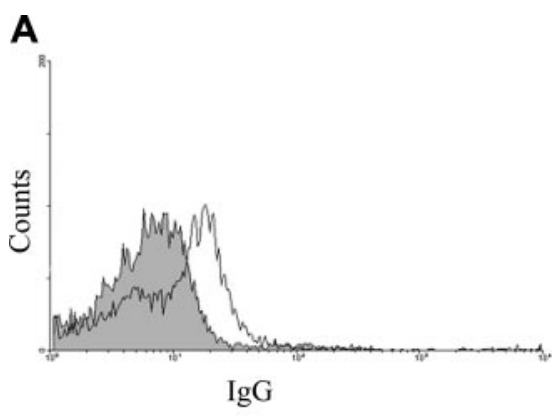

B

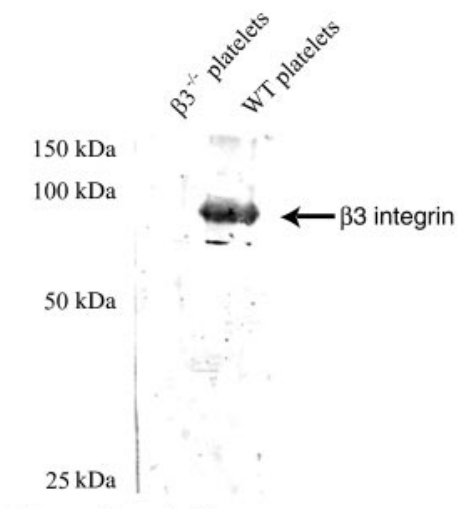

Western Blot: Antisera

Figure 2. Low-level antibody response in later pregnancies of naive female $\beta_{3}{ }^{-1-}$ mice after breeding 3 times with wild-type male mice. (A) Detection of antiplatelet IgG by flow cytometry. A 1:100 dilution of sera from the naive $\beta_{3}{ }^{-l-}$ mice was incubated with WT mouse platelets. Anti- $\beta_{3}$ integrin antibodies were detected at very low levels in sera from the mice after 3 pregnancies (thin line) compared with those from mice before breeding (filled area) by a flow cytometric assay. (B) Western blot of platelet antigens with a 1:1000 dilution of sera from the naive $\beta_{3}{ }^{-1-}$ mice. $\beta_{3}$ integrin was recognized by both the control antibody sc-6627 (data not shown) and the antisera from the naive $\beta_{3}{ }^{-l-}$ mice after 3 pregnancies.

"old" and generated fewer pups after 3 to 4 deliveries, it was difficult to compare the number of living pups and monitor their bleeding disorders with controls. Therefore, we used immunized female $\beta_{3}{ }^{-1-}$ mice in order to develop a mouse model for FNAITP in which high-titer anti- $\beta_{3}$ antibodies were generated and clinical FNAITP indices were observed. This protocol may mimic those women who have preconceptional exposure to $\beta_{3}$ integrin via either a previous pregnancy or exposure to sperm $\beta_{3}$ antigen ("Discussion").
We set up 8 breeding cages ( 1 female and 1 male mouse per cage) for WT males crossed with female $\beta_{3}{ }^{-1-}$ mice that had been immunized twice with WT platelets. The titer of antiplatelet IgG in these female mice was 1:800 (Figure 1B). We observed bleeding in some of the delivered pups (Figure 3Bii-iii); abdominal and skin bleeding as well as ICH were found in 7 of 54 live pups delivered from 6 female $\beta_{3}{ }^{-l-}$ mice at the first delivery (Table 1). The mortality rate was $24.1 \%$ (13 of 54 pups) due to internal organ bleeding, and 2 female $\beta_{3}{ }^{-l-}$ mice had miscarriages (Table 1). These findings were significantly different from those seen in the naive group (preimmunization) in both mortality rate $\left(\chi^{2}=8.10\right.$, $P<.005)$ and incidence of bleeding $\left(\chi^{2}=7.89, P<.005\right)$.

Because the relationship between antibody titer and the severity of FNAITP is controversial, ${ }^{15}$ we further studied $\beta_{3}{ }^{-1-}$ female mice which were immunized 4 times with WT platelet transfusions. As shown in Figure 1B, the titer of antibody in these mice was approximately 4 times higher than that of the twice-immunized mice. After breeding with WT male mice, 1 of the 3 immunized female $\beta_{3}{ }^{-1-}$ mice died during delivery after a 3-week pregnancy. Immediate autopsy showed that 3 mature-sized and 3 smaller fetuses were present in utero. Severe bleeding including ICH, abdominal hemorrhage, or both, was found in the 3 mature-sized fetuses (Figure $3 \mathrm{C}$ ). The other 2 pregnant female $\beta_{3}{ }^{-1-}$ mice had abortions or miscarriages after a 2- to 3-week pregnancy. No live pups were found and cannibalized remains of the neonates were present, which reflected a mortality rate that was significantly more severe than that of the twice-immunized mice $\left(\chi^{2}=4.96, P<.05\right)$. We further examined the reactivity of antiplatelet antibodies (immediately after delivery) from the 4-time-immunized mice, and found that it was 3- to 4-fold higher than that of twice-immunized mice. Thus, the titer of maternal IgG against $\beta_{3}$ integrin correlated with the severity of symptoms in this murine model (ie, 4-timeimmunized mice $>$ twice-immunized mice $>$ naive mice). Since no living pups were delivered from the $\beta_{3}{ }^{-1-}$ mice with high-titer antibody, we used female $\beta_{3}{ }^{-l-}$ mice transfused twice with WT platelets for most of the remaining experiments.

\section{Maternal anti- $\boldsymbol{\beta}_{3}$ integrin antibodies caused fetal and neonatal thrombocytopenia}

To test whether thrombocytopenia indeed occurred in neonates and contributed to the mentioned bleeding disorders in this murine model, we examined platelet counts in live heterozygous pups

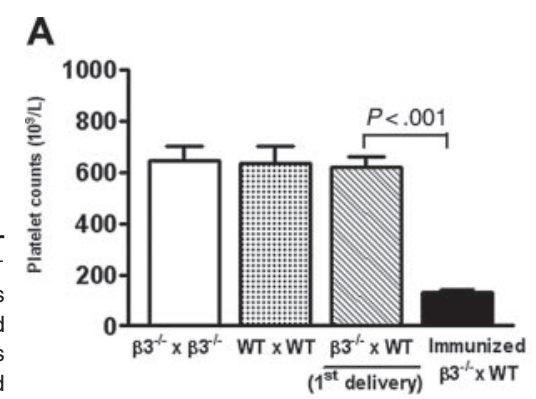

Figure 3. Spontaneous hemorrhage and thrombocytopenia in heterozygous progeny of immunized $\boldsymbol{\beta}_{3}{ }^{-1-}$ mothers. (A) Thrombocytopenia in heterozygous pups delivered from immunized $\beta_{3}{ }^{-1-}$ mothers (transfused twice with WT platelets) crossed with WT males. Pups from breeding cages of WT $\times \mathrm{WT}, \beta_{3}{ }^{-1-} \times \beta_{3}{ }^{-1-}$, and naive female $\beta_{3}{ }^{-1-} \times$ WT were used as a control. Data are presented as means \pm SEM; $n=7-25$ for each group. (B) Spontaneous bleeding in heterozygous pups delivered from immunized $\beta_{3}{ }^{-1-}$ mothers. (i) A heterozygous pup delivered from a naive $\beta_{3}{ }^{-1-}$ mother crossed with a WT male as a healthy control. (ii) Bleeding in live pups. (iii) Dead pups with massive $\mathrm{ICH}$ or abdominal bleeding. Bleeding is indicated by arrows. (C) Massive $\mathrm{ICH}$ and/or abdominal bleeding was found in fetuses in $\mathrm{B}_{3}{ }^{-1-}$ mice immunized with 4 weekly transfusions of WT platelets. (i) $\mathrm{ICH}$ and abdominal bleeding. (ii) $\mathrm{ICH}$.

\section{B}

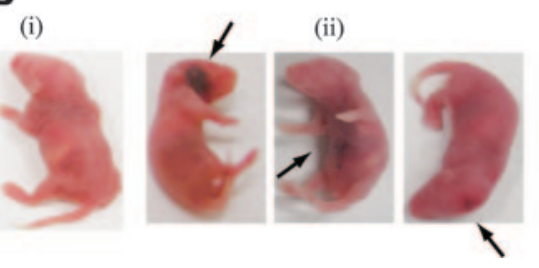

(iii)

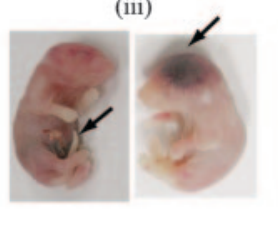

C

(i)

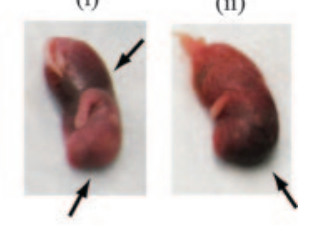


Table 1. Effect of maternal anti- $\beta_{3}$ integrin IgG and IVIG on fetal and neonatal bleeding disorders

\begin{tabular}{|c|c|c|c|c|c|}
\hline & $\begin{array}{l}\text { Breeding } \\
\text { cages }\end{array}$ & $\begin{array}{l}\text { Total } \\
\text { pups }\end{array}$ & $\begin{array}{l}\text { Dead } \\
\text { pups }\end{array}$ & $\begin{array}{l}\text { Bleeding } \\
\text { disorders }\end{array}$ & Miscarriage \\
\hline \multicolumn{6}{|l|}{ First delivery } \\
\hline$\beta_{3}^{-1-} \times \mathrm{WT} \dagger$ & 7 & 57 & 2\# & $0^{* *}$ & 0 \\
\hline Immunized $\beta_{3}^{-1-} \times$ WT $\ddagger$ & 8 & 54 & 13\#†† & $7^{\star \star}$ & 2 \\
\hline Immunized $\beta_{3}^{-1-} \times$ WT; IVIG§ & 2 & 12 & $\underline{0}$ & 0 & 0 \\
\hline \multicolumn{6}{|l|}{ Second delivery } \\
\hline Immunized $\beta_{3}^{-l-} \times \mathrm{WT} ; \mathrm{IVIG} \|$ & 5 & 36 & $1 \dagger \dagger$ & 2†‡ & 0 \\
\hline Immunized $\beta_{3}{ }^{-1-} \times$ WT albumin & 2 & 16 & 1 & $4 \ddagger \ddagger$ & 0 \\
\hline
\end{tabular}

Underlined value indicates that statistically significant difference was also observed compared with the immunized but IVIG-untreated group in the first delivery $\left(\chi^{2}>4.13\right.$; $P<.05)$.

${ }^{\star}$ Female $\beta 3^{-1-}$ mice delivered immature dead pups.

†Naive female $\beta 3^{-1-}$ mice (without immunization with WT platelets) were bred with WT male mice.

‡Female $\beta 3^{-1-}$ mice; first delivery after two times immunization with WT platelets.

$\S$ Female $\beta 3^{-1-}$ mice were transfused with IVIG during first delivery.

|Female $33^{-/-}$mice were transfused with IVIG during second delivery.

१Female $\beta 3^{-1-}$ mice were transfused with albumin as a control during second delivery.

$\# P<.005$. This and the following three footnotes indicate $P$ values for comparisons of the two values in the table sharing that footnote.

${ }^{* *} P<.005$.

$\dagger † P<.05$

$\ddagger \ddagger P<.05$.

delivered from female $\beta_{3}{ }^{-1-}$ mice immunized twice with WT platelet transfusions. Platelet counts in the pups were significantly decreased $\left(132.2 \pm 10.5 \times 10^{9} / \mathrm{L}\right.$ versus $618.3 \pm 42.5 \times 10^{9} / \mathrm{L}$ in control mice; $P<.001$ ) (Figure $3 \mathrm{~A}$ ). We were not able to examine the platelet counts in the dead pups, although more severe thrombocytopenia may have been expected. The platelet counts of pups delivered from naive female $\beta_{3}{ }^{-l-} \times$ WT male were similar to those of the pups delivered from WT $\times \mathrm{WT}$ and $\beta_{3}{ }^{-1-} \times \beta_{3}{ }^{-1-}$ mice (Figure 3A). Thus, maternal antibodies of the pregnant $\beta_{3}{ }^{-1-}$ mice, and not the genotype difference, were responsible for the reduction of platelet numbers in the heterozygous pups.

\section{Maternal anti- $\boldsymbol{\beta}_{3}$ integrin antibodies crossed the placenta and bound fetal and neonatal platelets}

Maternal antiplatelet IgG is the cause of FNAITP in human patients. To test whether neonatal thrombocytopenia was induced by maternal anti- $\beta_{3}$ integrin antibody in our mouse model, we examined circulating anti- $\beta_{3}$ integrin IgG and PAIgG in heterozygous pups delivered from the immunized $\beta_{3}{ }^{-1-}$ mice. As expected, antiplatelet $\operatorname{IgG}$ (Figure $4 \mathrm{~A}$ ) and $\operatorname{IgG}_{2 \mathrm{a}}(\mathrm{MFI}=5.13 \pm 0.2$ vs $3.77 \pm 0.1$ in controls; $P<.005)$ were detected in the sera of live heterozygous pups. The level of antibody from pups was approximately $10 \%$ of maternal antibody, which is similar to the relative antibody levels reported in human cases. ${ }^{16}$ Increased PAIgG was found on the surface of platelets from live pups with either low platelet counts and/or bleeding disorders (Figure 4B). There was no antiplatelet antibody detected in the different control groups, including pups delivered from the first 2 naive $\beta_{3}{ }^{-1-}$ female $\times \mathrm{WT}$ male litters. These results confirm that, in our murine model, maternal $\operatorname{IgG}$ crossed the placenta and bound to fetal platelets, concomitant with the clinical manifestations of FNAITP.

\section{IVIG ameliorated platelet counts and bleeding disorders in the FNAITP murine model}

We then evaluated the therapeutic efficacy of IVIG in our murine model of FNAITP using $\beta_{3}{ }^{-1}$ female mice that were transfused twice with WT platelets. These mice (which previously delivered FNAITP-affected neonates in the first pregnancy) were injected intravenously with IVIG once a week after being bred with WT male mice. As shown in Table 1, among the 36 pups which were delivered from 5 IVIG-treated female mice, 33 pups did not demonstrate any bleeding disorders, 2 pups had minor bleeding symptoms, and 1 pup was stillborn. The mortality rate was significantly decreased compared with the first litters that did not receive IVIG treatment $(P<.05)$. The platelet counts of these pups were elevated from $132.2 \pm 10.5 \times 10^{9} / \mathrm{L}$ to $353.3 \pm 18.0 \times 10^{9} / \mathrm{L}$ $(P<.001$; Figure 5A). Notably, when albumin was used in place of IVIG treatment in the same setting (second delivery), neonatal platelet counts remained low (Figure 5A) and bleeding disorders were similar to those of the first litters (Table 1). To exclude the contribution of differing number of pregnancies in the IVIGmediated amelioration, 2 female $\beta_{3}{ }^{-l-}$ mice immunized twice with WT platelets were injected intravenously with IVIG once a week during their first pregnancies. The platelet counts of the pups delivered from these female mice were also elevated to
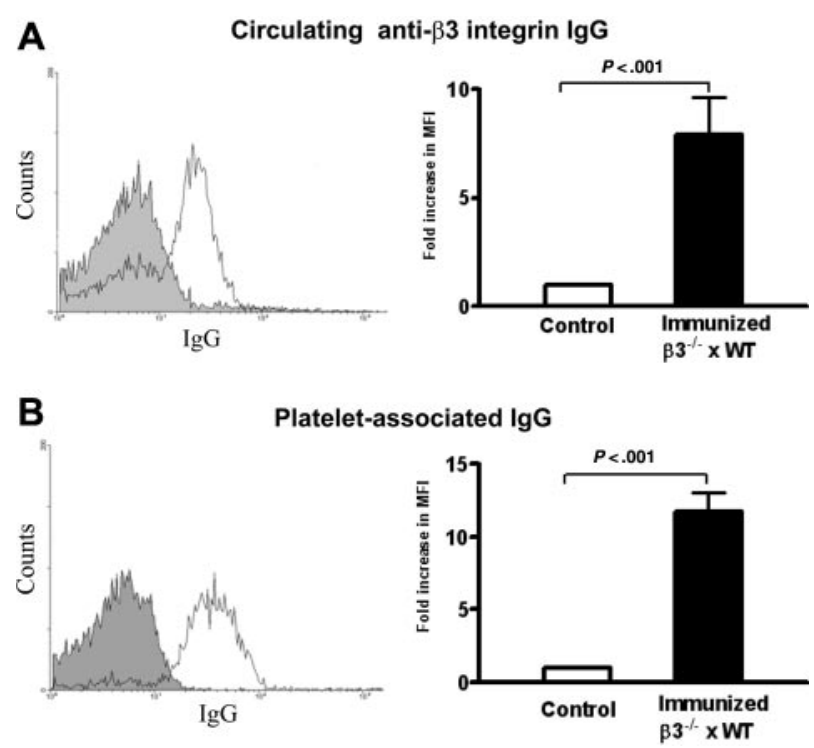

Figure 4. Circulating IgG and platelet-associated IgG in heterozygous pups delivered from immunized $\beta_{3}{ }^{-1-}$ mothers. (A) Circulating IgG against mouse $\beta_{3}$ integrin was detected in heterozygous pups (thin line) and pups of WT controls (filled area) by flow cytometry. (B) Platelet-associated IgG was detected in heterozygous pups (thin line) and pups of WT controls (filled area) by flow cytometry. Bar graphs represent means \pm SEM fold increase of circulating IgG and PAlgG from heterozygous pups versus WT pups; $n=5-12$. 


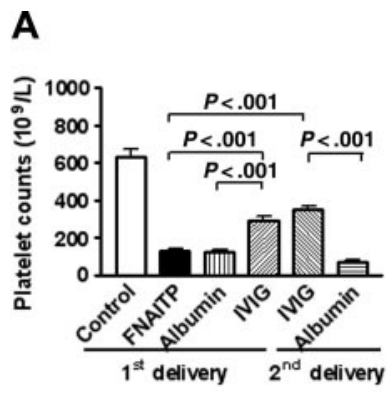

B
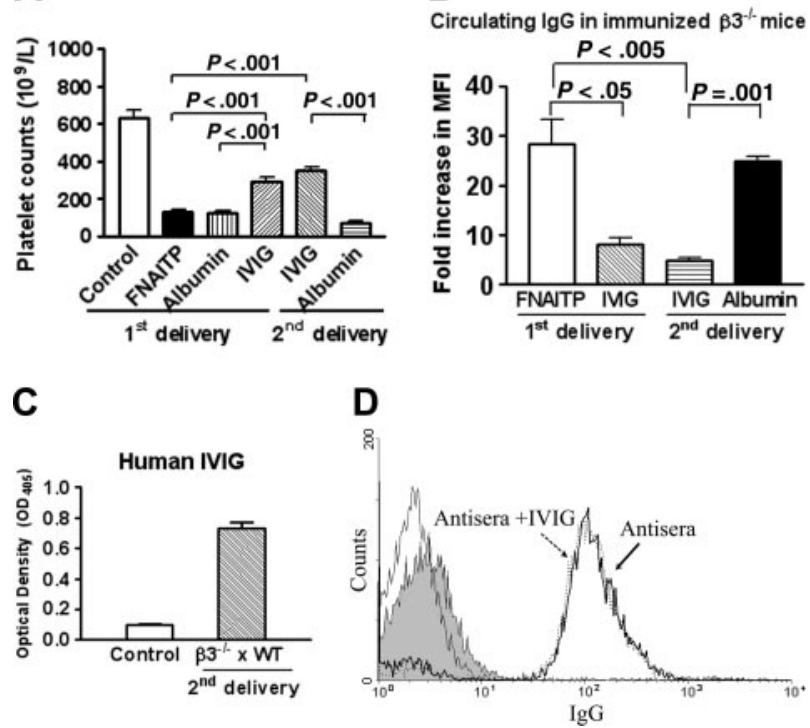

Figure 5. Effect of IVIG on neonatal platelet counts and maternal IgG levels. (A) Platelet counts in pups from breeding cages of WT $\times$ WT and $\beta_{3}{ }^{-1-} \times \beta_{3}{ }^{-1-}$ mice as a normal control, immunized female $\beta_{3}{ }^{-1-} \times W T$ mice (first delivery), immunized female $\beta_{3}{ }^{-1-} \times$ WT mice (treated with IVIG or albumin in their first delivery), and immunized female $\beta_{3}{ }^{-l-} \times$ WT mice (treated with IVIG or albumin in their second delivery). $n=12-22$. (B) IVIG decreased anti- $\beta_{3}$ integrin IgG in the maternal circulation. Sera of female $\beta_{3}{ }^{-1-}$ mice were incubated with $10^{6} \mathrm{WT}$ platelets at a final dilution of $1: 100$ for 1 hour. IgG anti-mouse $\beta_{3}$ integrin was detected by a flow cytometric assay $(n=2-3)$. There was no significant difference in antibody level between the first delivery (untreated) and the second delivery (albumin-treated), and between the first delivery and second delivery after IVIG treatment. (C) IVIG was detected by enzyme-linked immunosorbent assay (ELISA) in the sera of pups delivered from the IVIG-treated mothers during their second pregnancy. Sera of pups from the first delivery (ie, before IVIG treatment) were used as a negative control. $\mathrm{n}=3-5$ mice. (D) Anti-idiotype activity of IVIG was not found. Preincubated sera from immunized pregnant $\beta_{3}{ }^{-1-}$ mice with IVIG (dashed line; MFI $=145.2$ in 1:100 dilution) did not decrease antibody-platelet binding activity compared with sera alone (bold line; MFI = 152.0 in a 1:100 dilution). The thin solid line indicates IVIG alone incubated with mouse platelets. The filled area indicates that anti-human IgG-FITC did not bind to WT platelets incubated with IVIG plus antisera. Data are represented as means \pm SEM.

$292.5 \pm 23.3 \times 10^{9} / \mathrm{L}(P<.001 ;$ Figure $5 \mathrm{~A})$ and bleeding disorders were attenuated (Table 1). Not surprisingly, bleeding disorders and no significant decrease in circulating antibody (data not shown) and no amelioration in platelet counts (Figure 5A) have been found in the control albumin group. Furthermore, we tested the effect of IVIG on 1 of the female $\beta_{3}{ }^{-1-}$ mice transfused 4 times with WT platelets that had miscarriages during its first pregnancy. The female mouse delivered 5 live pups without obvious bleeding disorders in its second delivery, although the platelet counts of these live pups were still low $\left(198.6 \pm 24.9 \times 10^{9} / \mathrm{L}\right)$. These results indicate that, in our mouse model, IVIG is able to: (1) ameliorate the reduction of platelet counts; (2) ameliorate FNAITP bleeding symptoms; and (3) reduce mortality and miscarriage.

\section{IVIG decreased pathogenic antibodies in both the maternal and neonatal circulations}

As shown in Figure 5B, weekly administration of IVIG significantly decreased the level of $\operatorname{IgG}$ anti- $\beta_{3}$ integrin in the immunized $\beta_{3}{ }^{-1-}$ mothers during their second pregnancies $(P<.005)$. The level of anti- $\beta_{3}$ integrin antibody (MFI) was decreased from 28.3to 4.6-fold relative to sera from the maternal circulation during their first pregnancies. Furthermore, neither circulating antibody nor PAIgG were detectable in the neonates (data not shown). A similar down-regulatory effect of IVIG on antibody levels was seen in immunized $\beta_{3}^{-1-}$ mothers during their first pregnancies $(P<.05)$. In control groups, which were treated with albumin, the level of maternal IgG anti- $\beta_{3}$ integrin did not significantly decrease in the circulation (Figure 5B). We also found that IVIG administered to pregnant mothers was able to cross the placenta since it was detected in the sera of the heterozygous pups (Figure 5C).

To determine whether anti-idiotypic antibodies were present in IVIG and played a role in decreasing the titers and attenuating immunoreactivity of maternal $\mathrm{IgG}$, sera from $\beta_{3}{ }^{-1-}$ mothers immunized 4 times were preincubated with IVIG before being incubated with WT platelets. No decrease of MFI was observed for maternal IgG binding to platelets in the presence of IVIG. There was also no IVIG binding to other portions (ie, agretope) of anti- $\beta_{3}$ antibodies as determined by our flow-cytometric assay (Figure 5D). We also did not detect IVIG binding to the antibodies generated from $\beta_{3}{ }^{-l-}$ mothers that were immunized twice (data not shown). These results suggested that anti-idiotypic antibodies were not present in IVIG and may not be responsible for ameliorating FNAITP in this murine model.

\section{Discussion}

In the present study, we report the first animal model of FNAITP. Our results showed that murine antibodies against murine $\beta_{3}$ integrin were generated in $\beta_{3}{ }^{-1-}$ mice. Breeding immunized female $\beta_{3}{ }^{-1-}$ mice with WT male mice reproduced the clinically relevant fetal bleeding disorders exhibited in human cases of FNAITP. This model demonstrates: (1) maternal antiplatelet antibodies correlate with the severity of the observed FNAITP phenotype; (2) maternal IVIG administration has multiple effects on the amelioration of this disorder, including decreased maternal antiplatelet antibody, depleted pathogenic antibody in the neonatal circulation, decreased fetal platelet clearance, reduced bleeding disorders, and increased fetal survival; and (3) the mechanism of action of IVIG is likely not due to an anti-idiotype antibody effect. To our knowledge, this is the first report that IVIG is able to decrease maternal and fetal pathogenic antibody levels during pregnancy.

In human patients, approximately $50 \%$ of FNAITP cases occur in the first pregnancy, and are apparent following delivery. It is therefore usually difficult to identify these FNAITP patients and to monitor their maternal immune responses during pregnancy. FNAITP is often complicated with severe bleeding disorders, including ICH and other internal organ hemorrhages. After diagnosis, immediate therapeutic action is required and it is ethically impossible to set an untreated control to investigate this lifethreatening disease in the human population. Thus, an animal model is important to study the pathogenesis of FNAITP and to monitor potential therapeutic effects. While several models of other immune thrombocytopenia have been reported, ${ }^{17-19}$ no previous animal model of FNAITP exists.

We demonstrated that $\beta_{3}{ }^{-1-}$ mice were immunoresponsive against murine $\beta_{3}$ integrin and both Th1- and Th2-associated $\operatorname{IgG}_{2 \mathrm{a}}$ and $\mathrm{IgG}_{1}$ isotypes, respectively, were produced. Th1-like immune responses have been shown to affect the pathogenesis of ITP and its treatment. ${ }^{20,21}$ Although the relevance of both isotypes being produced in FNAITP is unknown, the presence of complementfixing $\operatorname{IgG}_{2 \mathrm{a}}$ may be of significance to the pathogenesis of FNAITP in that platelet destruction can occur by at least 2 different mechanisms (Fc-dependent phagocytosis and complement activation). 
After demonstrating immune responsiveness to $\beta_{3}$ integrin, we bred female naive $\beta_{3}{ }^{-1-}$ mice with WT male mice. In contrast to human FNAITP, we did not observe significant bleeding disorders following the first delivery, or even the second delivery. This difference between mice and humans may be due to the short period of pregnancy in mice; the time could be too short to generate a significant immune response, in particular during the physiologic immunosuppressive state of pregnancy. ${ }^{22}$ Another potential explanation is that many women may have been exposed to HPAs (eg, $\beta_{3}$ integrin) prior to pregnancy. It has been reported that $\beta_{3}$ integrin is expressed in sperm. ${ }^{23}$ Thus, it is possible that preconceptional intercourse may prime the human female immune system and subsequent exposure to fetal $\beta_{3}$ integrin alloantigen during pregnancy may boost the immune response and result in an FNAITP phenotype. Our preliminary data that sera from some pregnant women with FNAITP indeed recognized a sperm antigen at the same molecular mass as $\beta_{3}$ integrin (C.M.S. and H.N., unpublished data, October 2004) support this hypothesis. The $\beta_{3}{ }^{-1-}$ female mice immunized with WT platelet transfusions in this model may mimic such preconceptional exposure (or that of human mothers who have had previous pregnancies) in human FNAITP.

Our murine model was established by breeding $\beta_{3}{ }^{-l-}$ female mice with WT male mice. This situation, however, may differ from that of human patients. In human FNAITP cases, alloantibodies are mainly formed against the polymorphic structure of the $\beta_{3}$ integrin chain, which might recognize different epitopes and therefore might have different properties compared with the antibodies developed in this animal model. In addition, although FcRn has been reported to be responsible for maternofetal IgG transfer in both human and rodents, transfer of $\mathrm{IgG}$ in humans shows increased specificity (with respect to murine transfer), and there is preferential transport of some isotypes over others. ${ }^{24}$ However, the process of immune responsiveness and the pathogenesis of FNAITP between human and mouse may be comparable. In fact, all clinical indices and symptoms were well reproduced in this model. We also found that maternal antibody titer correlated with the severity of bleeding disorders and that a high titer of anti- $\beta_{3}$ integrin antibody may even induce miscarriage. The heterogeneity of the experimental picture in heterozygous pups is similar to that seen in humans. The sites of bleeding may depend on the site of trauma during pregnancy and delivery (eg, relative nonprotection of abdominal organs or the large size of the head). Also, we speculate that some anti- $\beta_{3}$ antibodies may cross-react with endothelial cells and cause vessel injury, which may enhance the severity of FNAITP and affect the sites of bleeding.

The management of FNAITP is a challenge; currently, the most effective antenatal therapy is weekly in utero platelet transfusions using irradiated maternal/antigen-negative platelets. In addition to technical difficulties associated with this procedure, this invasive procedure may also cause bleeding, fetal trauma, and spontaneous abortion. However, IVIG has been used to treat ITP patients since $1981^{25}$ and later to treat FNAITP ${ }^{1,10}$ The proposed mechanisms of action of IVIG in ITP include: (1) reticuloendothelial system (RES) blockade; ${ }^{11}$ (2) anti-idiotypic antibody activity; ${ }^{26}$ (3) induction of T- and B-cell tolerance; ${ }^{27-29}$ (4) inhibition of dendritic-cell function; ${ }^{30}$ and (5) inhibition of macrophage phagocytosis via IVIG/ Fc $\gamma$ RIIB interaction. ${ }^{12,31}$ Recently, the role of FcRn in homeostasis of $\mathrm{IgG}$ has been highlighted. ${ }^{32} \mathrm{FcRn}$ may protect IgG from proteolysis during transcytosis in epithelial and endothelial cells. ${ }^{33,34}$ Thus, IVIG may saturate FcRn and consequently promote the accelerated clearance of pathogenic $\operatorname{IgG} .{ }^{35,36} \mathrm{In}$ fact, it has been reported that IVIG may enhance the clearance of pathogenic IgG by this mechanism in both ITP $^{37}$ and rheumatoid arthritis. ${ }^{7}$ However, the mechanism of action of IVIG in FNAITP remains to be elucidated. Although significant amelioration of FNAITP was observed in our model, it is unclear whether: (1) T- and B-cell tolerance is induced by IVIG in the maternal immune system, which decreases pathogenic IgG production; (2) enhancement of antibody proteolysis indeed occurs in pregnant mothers after IVIG administration; (3) IVIG saturates FcRn in the placenta and blocks maternal antibody transplacental transportation; (4) RES blockade also occurs in the fetus; (5) the improved prognosis of maternalcompared with in utero-IVIG administration in a previous case report $^{38}$ was due to the synergistic actions of the described mechanisms; and finally (6) whether variation of the efficacy of IVIG treatment in human FNAITP results from different sources and dosages of IVIG $^{39}$ used in different therapeutic regimens. Our murine model offers a convenient means of addressing these questions.

In summary, we have established an animal model of FNAITP that reproduced the symptoms of human FNAITP. We demonstrated that anti- $\beta_{3}$ integrin antibody may cause abortion and miscarriage, and that maternal IVIG administration has a systemic effect on amelioration of this disease. Our data that IVIG can down-regulate pathogenic antibody in the maternal circulation may have broad implications for other mother-antifetal antigen-related diseases such as hemolytic disease caused by $\mathrm{Rh}$ antigen. This model will be important for further investigation of the maternal immune response and pathogenesis of FNAITP.

\section{Acknowledgments}

The authors would like to thank Dr Victor S. Blanchette and Dr Gregory A. Denomme for their advice during the experiments. Dr Bernhard Nieswandt provided anti-mouse GPIb $\alpha$ (p0p3) and anti-mouse $\alpha_{\mathrm{IIb}} \beta_{3}$ integrin (JON2) monoclonal antibodies.

\section{References}

1. Bussel J, Kaplan C. The fetal and neonatal consequences of maternal alloimmune thrombocytopenia. Baillieres Clin Haematol. 1998;11:391-408.

2. Dreyfus M, Kaplan C, Verdy E, Schlegel N, Durand-Zaleski I, Tchernia G. Frequency of immune thrombocytopenia in newborns: a prospective study: Immune Thrombocytopenia Working Group. Blood. 1997;89:4402-4406.

3. Bussel JB, Zabusky MR, Berkowitz RL, McFarland JG. Fetal alloimmune thrombocytopenia. N Engl J Med. 1997;337:22-26.

4. Metcalfe P, Watkins NA, Ouwehand WH, et al. Nomenclature of human platelet antigens. Vox Sang. 2003;85:240-245.
5. Williamson LM, Hackett G, Rennie J, et al. The natural history of fetomaternal alloimmunization to the platelet-specific antigen HPA-1a (PIA1, Zwa) as determined by antenatal screening. Blood. 1998;92:2280-2287.

6. Newman PJ, Valentin N. Human platelet alloantigens: recent findings, new perspectives. Thromb Haemost. 1995;74:234-239.

7. Akilesh S, Petkova S, Sproule TJ, Shaffer DJ, Christianson GJ, Roopenian D. The MHC class I-like $\mathrm{Fc}$ receptor promotes humorally mediated autoimmune disease. J Clin Invest. 2004;113: 1328-1333.

8. Yoshida M, Claypool SM, Wagner JS, et al. Human neonatal Fc receptor mediates transport of IgG into luminal secretions for delivery of antigens to mucosal dendritic cells. Immunity. 2004;20:769-783.

9. Hassan NM, Neiman RS. The pathology of the spleen in steroid-treated immune thrombocytopenic purpura. Am J Clin Pathol. 1985;84:433-438.

10. Kaplan C, Murphy MF, Kroll H, Waters AH. Fetomaternal alloimmune thrombocytopenia: antenatal therapy with IvlgG and steroids: more questions than answers: European Working Group on FMAIT. Br J Haematol. 1998;100:62-65.

11. Crow AR, Song S, Semple JW, Freedman J, Lazarus AH. IVIg inhibits reticuloendothelial 
From www.bloodjournal.org by on January 13, 2009. For personal use only.

system function and ameliorates murine passiveimmune thrombocytopenia independent of antiidiotype reactivity. Br J Haematol. 2001;115:679 686.

12. Samuelsson A, Towers TL, Ravetch JV. Antiinflammatory activity of IVIG mediated through the inhibitory Fc receptor. Science. 2001;291:484-486.

13. Bayry J, Misra N, Latry V, et al. Mechanisms of action of intravenous immunoglobulin in autoimmune and inflammatory diseases. Transfus Clin Biol. 2003;10:165-169.

14. Hodivala-Dilke KM, McHugh KP, Tsakiris DA, et al. Beta3-integrin-deficient mice are a model for Glanzmann thrombasthenia showing placental defects and reduced survival. J Clin Invest. 1999; 103:229-238.

15. Killie M HA, Kjeldsen-Kragh J, Skogen B. The natural course of anti-HPA 1a antibody levels in subsequent non-compatible pregnancies [abstract]. 8th European Symposium on Platelet and Granulocyte Immunobiology. Rust, Burgenland, Austria; 2004:COM16.

16. Malek A. Ex vivo human placenta models: transport of immunoglobulin $\mathrm{G}$ and its subclasses. Vaccine. 2003;21:3362-3364.

17. Oyaizu N, Yasumizu R, Miyama-Inaba M, et al. (NZW x BXSB)F1 mouse: a new animal model of idiopathic thrombocytopenic purpura. J Exp Med. 1988;167:2017-2022.

18. Dekel B, Marcus H, Shenkman B, et al. Human/ BALB radiation chimera engrafted with splenocytes from patients with idiopathic thrombocytopenic purpura produce human platelet antibodies. Immunology. 1998;94:410-416.

19. Hansen RJ, Balthasar JP. Pharmacokinetics, pharmacodynamics, and platelet binding of an anti-glycoprotein Ilb/IIla monoclonal antibody (7E3) in the rat: a quantitative rat model of immune thrombocytopenic purpura. J Pharmacol Exp Ther. 2001;298:165-171.

20. Semple JW, Milev Y, Cosgrave D, et al. Differ- ences in serum cytokine levels in acute and chronic autoimmune thrombocytopenic purpura: relationship to platelet phenotype and antiplatelet T-cell reactivity. Blood. 1996;87:4245-4254.

21. Panitsas FP, Theodoropoulou M, Kouraklis A, et al. Adult chronic idiopathic thrombocytopenic purpura (ITP) is the manifestation of a type-1 polarized immune response. Blood. 2004;103:26452647.

22. Aluvihare VR, Kallikourdis M, Betz AG. Regulatory $T$ cells mediate maternal tolerance to the fetus. Nat Immunol. 2004;5:266-271.

23. Fusi FM, Tamburini $C$, Mangili F, Montesano M, Ferrari A, Bronson RA. The expression of alpha $v$, alpha 5 , beta 1 , and beta 3 integrin chains on ejaculated human spermatozoa varies with their functional state. Mol Hum Reprod. 1996;2:169175.

24. Ghetie V, Ward ES. Multiple roles for the major histocompatibility complex class I- related receptor FcRn. Annu Rev Immunol. 2000;18:739-766.

25. Imbach P, Barandun S, Baumgartner C, Hirt A, Hofer F, Wagner HP. High-dose intravenous gammaglobulin therapy of refractory, in particular idiopathic thrombocytopenia in childhood. Helv Paediatr Acta. 1981;36:81-86.

26. Berchtold P, McMillan R. Therapy of chronic idiopathic thrombocytopenic purpura in adults. Blood. 1989;74:2309-2317.

27. de Grandmont MJ, Racine C, Roy A, Lemieux R, Neron S. Intravenous immunoglobulins induce the in vitro differentiation of human $B$ lymphocytes and the secretion of IgG. Blood. 2003;101: 3065-3073.

28. Tsubakio T, Kurata Y, Katagiri S, et al. Alteration of $T$ cell subsets and immunoglobulin synthesis in vitro during high dose gamma-globulin therapy in patients with idiopathic thrombocytopenic purpura. Clin Exp Immunol. 1983;53:697-702.

29. Macey MG, Newland AC. CD4 and CD8 subpopulation changes during high dose intravenous immunoglobulin treatment. Br J Haematol. 1990; 76:513-520.

30. Bayry J, Lacroix-Desmazes S, Carbonneil C, et al. Inhibition of maturation and function of dendritic cells by intravenous immunoglobulin. Blood. 2003;101:758-765.

31. Ravetch JV, Lanier LL. Immune inhibitory receptors. Science. 2000;290:84-89.

32. Ghetie V, Ward ES. FcRn: the MHC class Irelated receptor that is more than an IgG transporter. Immunol Today. 1997;18:592-598.

33. Antohe F, Radulescu L, Gafencu A, Ghetie V, Simionescu M. Expression of functionally active FcRn and the differentiated bidirectional transport of IgG in human placental endothelial cells. Hum Immunol. 2001;62:93-105.

34. Ahouse JJ, Hagerman CL, Mittal P, et al. Mouse MHC class I-like Fc receptor encoded outside the MHC. J Immunol. 1993;151:6076-6088.

35. Bleeker WK, Teeling JL, Hack CE. Accelerated autoantibody clearance by intravenous immunoglobulin therapy: studies in experimental models to determine the magnitude and time course of the effect. Blood. 2001;98:3136-3142.

36. Yu Z, Lennon VA. Mechanism of intravenous immune globulin therapy in antibody-mediated autoimmune diseases. N Engl J Med. 1999;340:227228.

37. Hansen RJ, Balthasar JP. Effects of intravenous immunoglobulin on platelet count and antiplatelet antibody disposition in a rat model of immune thrombocytopenia. Blood. 2002;100:2087-2093.

38. Bowman J, Harman C, Mentigolou S, Pollock J. Intravenous fetal transfusion of immunoglobulin for alloimmune thrombocytopenia. Lancet. 1992;340:1034-1035.

39. Teeling JL, Jansen-Hendriks T, Kuijpers TW, et al. Therapeutic efficacy of intravenous immunoglobulin preparations depends on the immunoglobulin G dimers: studies in experimental immune thrombocytopenia. Blood. 2001;98:10951099. 